\title{
A review of the assessment and prevalence of sedentarism in older adults, its physiology/health impact and non-exercise mobility counter-measures
}

\author{
Jorgen A. Wullems • Sabine M. P. Verschueren · Hans Degens • \\ Christopher I. Morse • Gladys L. Onambélé
}

Received: 2 March 2015/ Accepted: 19 February 2016/Published online: 14 March 2016

(C) The Author(s) 2016. This article is published with open access at Springerlink.com

\begin{abstract}
This literature review focuses on aspects of sedentary behaviour (SB) in elderly. Since it has been identified as a distinct health risk, independent of physical activity, SB is a significant issue. This is particularly true for an ageing population as evidence shows that older adults (aged $\geq 65$ years) are the most sedentary age group (on average 8.5-9.6 h daily sitting time). Accurate SB assessment is important for understanding this habitual behaviour and its impact. However, SB measurement is challenging, regardless of the method used. Although negative associations of SB in elderly have been reported for several health outcomes, evidence is inconclusive, apart from the evidence on the adverse SB effect on the all-cause mortality rate. Generally, strategies have
\end{abstract}

J. A. Wullems · C. I. Morse · G. L. Onambélé ( $\square)$ Department of Exercise and Sport Science, Institute for Performance Research, Manchester Metropolitan University, Crewe Green Road, Crewe CW1 5DU, UK e-mail: g.pearson@mmu.ac.uk

\section{S. M. P. Verschueren}

Musculoskeletal Rehabilitation Research Group, Department of Rehabilitation Sciences, KU Leuven, Louvain, Belgium

H. Degens

School of Healthcare Science, Manchester Metropolitan University, Manchester, UK

H. Degens

Lithuanian Sports University, Kaunas, Lithuania been proposed to counteract SB, of which breaking prolonged sedentary bouts with at least light-intensity physical activity seems to be the most promising. Overall, further research in elderly is required to increase the evidence and to either support or refute the current findings. Moreover, further research will help to develop informed SB guidelines for an optimal strategy to counteract SB and its health effects in older adults.

Keywords Ageing physiology $\cdot$ Musculoskeletal · Older adults $\cdot$ Physical activity $\cdot$ Sedentary behaviour

\section{Introduction}

Contrary to general perceptions, sedentary behaviour (SB) does not necessarily reflect a lack of physical activity (PA) (Sedentary Behaviour Research Network 2012). Instead, SB is defined as any waking behaviour characterized by an energy expenditure $\leq 1.5$ metabolic equivalent of task (MET) while in a seated or reclined posture (Sedentary Behaviour Research Network 2012). Currently, time spent sitting is increasing in modern societies, presumably linked to activities related to work, leisure or commuting. Previous research has shown that higher sitting time is related to poorer health (Gardiner et al. 2011c; Inoue et al. 2012). Recent health improvement strategies have focused on increasing PA (Kikuchi et al. 2014). While 
PA contributes to healthy ageing and plays a key role in the prevention of non-communicable diseases and disability, including cardiovascular disease, cancer, metabolic syndrome, mental disorders, musculoskeletal diseases and even all-cause mortality (de Rezende et al. 2014a; Gorman et al. 2014; Gennuso et al. 2015), studies that controlled for PA intensity provide evidence that also (prolonged) SB is an independent determinant of health (Gennuso et al. 2013; Gorman et al. 2014; de Rezende et al. 2014b; Gianoudis et al. 2015). This has led to the proposal of a novel stratagem for reducing health risks through not only increasing PA, but also decreasing SB (Hamilton et al. 2008; Owen et al. 2011).

Recently, the study of SB and its relation to health has become more popular (de Rezende et al. 2014a), but at present most underlying mechanisms by which SB has deleterious health effects remain unknown (Gianoudis et al. 2015). Moreover, existing studies have generally focused on different outcome measures and presented divergent conclusions, making the formulation of a cohesive understanding of the interaction between SB and health, as yet, impossible (de Rezende et al. 2014b). Although SB research shows that older adults (aged $\geq 65$ years) are the most sedentary, this age group has only been studied limitedly (Gennuso et al. 2013; Van Cauwenberg et al. 2014b). This makes it difficult to allow policy recommendations giving detailed information on how to reduce SB in older adults (Harvey et al. 2013). With an ageing population, the increased SB is challenging for both health and social care resources, and better understanding of the relationship between SB and health in the elderly requires more and better-targeted research (de Rezende et al. 2014a). To aid in developing targeted research programmes it is important to identify and summarize current findings of SB in older adults.

Hence, the aim of this review was to describe multiple aspects of SB in older adults, from its assessment, prevalence, physiology, health impact, through to any known potential counteracting strategies.

The strategy used to meet the aims of this literature review was based on a search in four different electronic databases (PubMed, CINAHL, The Cochrane Library and Sedentary Behaviour Research Database) combining the following key words: "sedentary behaviour", "older adults", and "health". Where possible, the following search limits were used: English language and age group 65+. This search (performed on 02 December 2015) identified 825 peerreviewed articles. All were screened for potential inclusion based first on the title and abstract, and if not excluded, the full-texts were checked for eligibility. Generally, eligible articles focused on SB (or a proxy measure, but not physical inactivity) as a main independent or dependent variable in healthy, community-dwelling older adults (aged $\geq 60$ years) only. In addition to the electronic databases search, reference lists of the eligible articles $(n=41)$ were handsearched to identify any missed papers $(n=7)$ (Fig. 1). Table 1 shows an overview of the 48 included papers, which are fundamental to this review.

\section{Assessment of sedentary behaviour}

Similar to characterising PA and exercise by the FITT formula, describing the Frequency, Intensity, Time (duration) and Type of activity, SB is suggested to be characterised by the SITT formula, which describes Sedentary behaviour frequency, number of Interruptions, Time (duration) and Type (Tremblay et al. 2010). These variables provide valuable information on SB and should therefore be assessed in any study dealing with SB. Since the need to quantify SB emerged, efforts have been undertaken to develop suitable measurement techniques. Overall, these can be classified as either subjective or objective, and both have different outcome measures. According to previous research (Pate et al. 2008; Chastin and Granat 2010; Pedišić and Bauman 2015), studies on SB initially relied on self-reported methods, such as questionnaires and/or logs. Subjective methods are practical, easy to administer, inexpensive, useful in large-scale studies and do not alter behaviour (CelisMorales et al. 2012; Chastin et al. 2014a; AguilarFarías et al. 2015). They will provide SB outcomes in terms of total sitting time, total screen time or TV time. If surrogate or proxy SB measures (e.g. TV viewing or total screen time) are used as an indicator of total SB, conclusions can however only be drawn limited to the used measures, because the association with total objective SB seems rather weak, even if the proxy measure is objective (Pate et al. 2008; Visser and Koster 2013; Chastin et al. 2014a). Although the number of SB questionnaires for older adults increases and quality improves in terms of acceptable reliability measures, validity of self-reported total sedentary time 


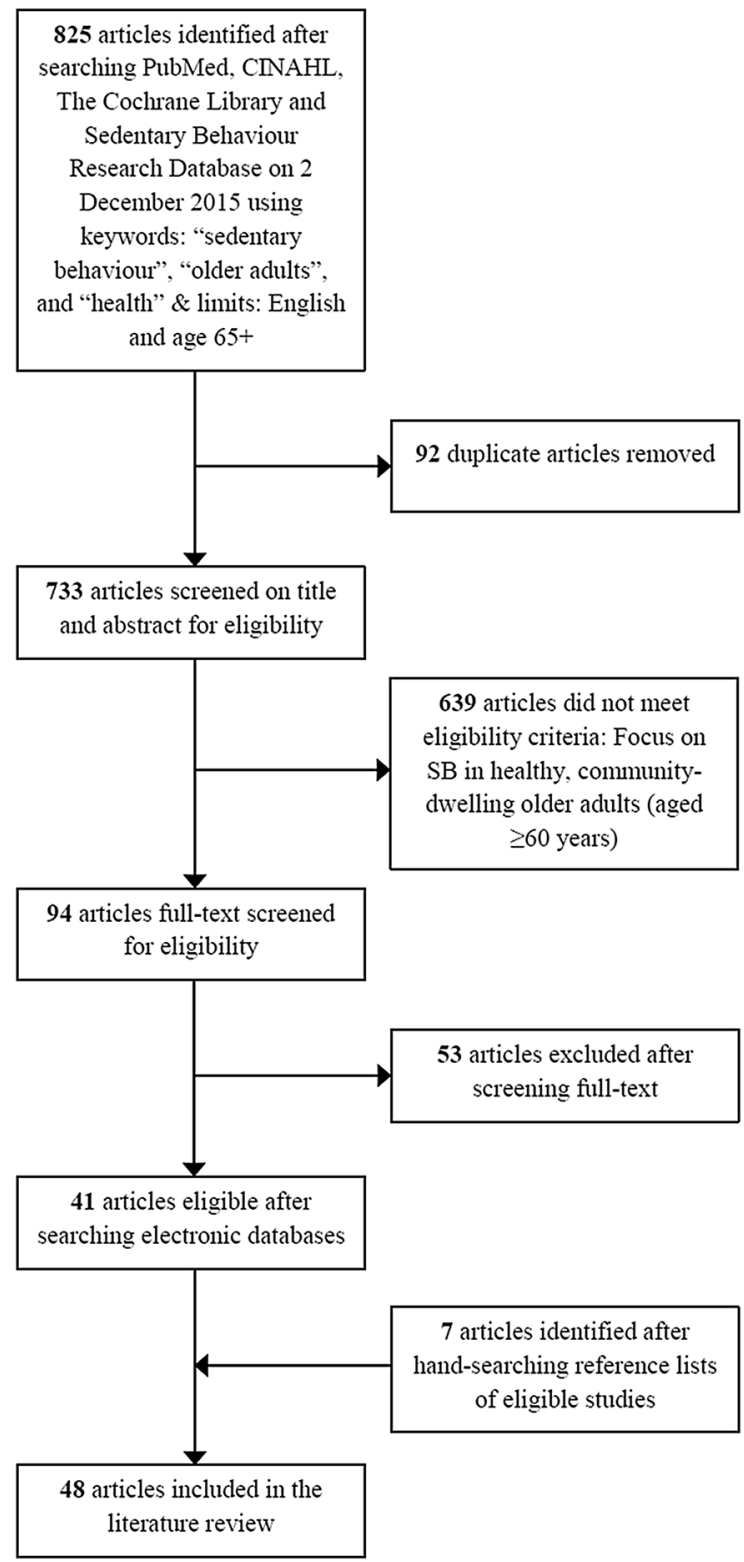

Fig. 1 Literature search flow diagram

against accelerometer-derived SB is not strong yet (Gardiner et al. 2011a; Hekler et al. 2012; Visser and Koster 2013; Van Cauwenberg et al. 2014b; AguilarFarías et al. 2015). A major flaw is that most studies validate questionnaires against sensors unable to capture SB accurately due to the inability of measuring postural orientation, e.g. thigh inclination (Chastin et al. 2014a). Generally, most subjective measures have obvious caveats, like bias and the tendency to under-report SB (Chastin and Granat 2010; Harvey et al. 2015; Aguilar-Farías et al. 2015). SB appears to be more difficult to recall than PA, because of its habitual nature (Hart et al. 2011; Bond et al. 2014). Especially for older adults it is a challenge to accurately estimate sitting-time (van Uffelen et al. 2011). The combination of underestimation and low precision is likely to reduce the ability to accurately detect dose-response relationships between self-reported SB and health outcomes (Chastin et al. 2014a). Nevertheless, so-called past or previous day recall questionnaires have been reported as promising since they are easy-to-administer, compare favourably with other sedentary time questionnaires, criterion validity is high, and systematic errors low (Clark et al. 2013; Matthews et al. 2013). Self-reports might give a detailed picture of how, where and why SB time is spent, which could be essential for developing interventions and public policy (Rhodes et al. 2012; Matthews et al. 2013; Kozey Keadle et al. 2014; Van Cauwenberg et al. 2014b; Busschaert et al. 2015). Thus, subjective methods can provide useful information and should not be ignored in SB assessment, but they should not be used as sole means to assess $\mathrm{SB}$, and the development of accurate self-report tools to measure (specific) SB in elderly is still required (Van Cauwenberg et al. 2014b; Gennuso et al. 2015).

Although many objective techniques are available to capture PA, there are only few to measure SB, in particular accelerometers (Tremblay et al. 2010). Accelerometry is preferred by most studies since it provides reliable and valid measures of both PA and $\mathrm{SB}$, and it overcomes many of the above-mentioned limitations of self-reports (Evenson et al. 2012; Gorman et al. 2014; Lohne-Seiler et al. 2014; Aguilar-Farías et al. 2014; Pedišić and Bauman 2015). However, it is important to mention that different accelerometers use distinct methods to measure SB. One quantifies SB by a lack of movement, and the other by postural allocation. The first type only uses estimates of energy expenditure in combination with cut-off points to define SB. However this results in misclassification as standing is difficult to distinguish from sitting when performed below the sedentary cut-off point (Stamatakis et al. 2012; Aguilar-Farías et al. 2014). Devices measuring postural allocation are more accurate in assessing SB and therefore not only recommended but also used as reference standard (Kozey-Keadle et al. 2011; Aguilar-Farías et al. 2014). When compared to self-reports, 
Table 1 Overview of the 48 included studies after literature search

\begin{tabular}{llll}
\hline $\begin{array}{l}\text { Data presented in } \\
\text { paragraph(s) }\end{array}$ & Author(s) & $\begin{array}{l}\text { Study } \\
\text { population }\end{array}$ & $\begin{array}{l}\text { Subjective or } \\
\text { objective SB } \\
\text { tool }\end{array}$
\end{tabular}

Original studies

Assessment of SB

Prevalence and types of SB

$\begin{array}{lll}\text { Van } & \mathrm{n}=508 & \text { Both } \\ \begin{array}{ll}\text { Cauwenberg } \\ \text { et al. (2014b) }\end{array} & & \\ \begin{array}{c}\text { Aguilar-Farías } \\ \text { et al. (2014) }\end{array} & \mathrm{n}=37 & \text { Objective }\end{array}$

$\begin{array}{lll}\begin{array}{l}\text { Hekler et al. } \\ \text { (2012) }\end{array} & \mathrm{n}=870 & \text { Both } \\ \begin{array}{l}\text { van Uffelen } \\ \text { et al. (2011) }\end{array} & \mathrm{n}=55 & \text { Subjective } \\ \begin{array}{l}\text { Gardiner et al. } \\ \text { (2011a) }\end{array} & \mathrm{n}=48 & \text { Both }\end{array}$

Shiroma et al. $\mathrm{n}=7247 \quad$ Objective (2013)

Arnardottir $\quad \mathrm{n}=579 \quad$ Objective et al. (2013)

Evenson et al. $\mathrm{n}=760 \quad$ Objective (2014)

Evenson et al. $\quad \mathrm{n}=2630 \quad$ Objective (2012)

Lord et al. $\mathrm{n}=56 \quad$ Objective (2011)

Jefferis et al. $\quad \mathrm{n}=1419 \quad$ Objective (2015a)

Health impact of SBMusculoskeletal health \& functional fitness

$\begin{array}{lll}\begin{array}{c}\text { Mitchell et al. } \\ \text { (2015) }\end{array} & \mathrm{n}=5681 & \text { Subjective } \\ \begin{array}{c}\text { Gianoudis } \\ \text { et al. (2015) }\end{array} & \mathrm{n}=162 & \text { Subjective } \\ & & \\ \begin{array}{c}\text { Dunlop et al. } \\ \text { (2015) }\end{array} & \mathrm{n}=2286 & \text { Objective }\end{array}$

Validity for older adults' self-reported total sitting time against accelerometer-derived sedentary time was not strong, but comparable to previous studies

The results suggest that cut-points are dependent on unit of analyses (i.e. epoch length and axes); cutpoints for a given epoch length and axis cannot simply be extrapolated to other epoch lengths

CHAMPS items effectively measured high-light, total activity, and MVPA in seniors, but further refinement is needed for sedentary and low-light activity

The accuracy of older adults' self-reported sitting time is questionable given the challenges they have in answering sitting-time questions

The summary measure of total sedentary time has good repeatability and modest validity and is sufficiently responsive to change suggesting that it is suitable for use in interventions with older adults

Older women spent about two-thirds of waking time in $\mathrm{SB}$, most of which occurred in bouts lasting less than $30 \mathrm{~min}$

Sedentary time is high in Icelandic older adults who have high life-expectancy and live north of $60^{\circ}$ northern latitude, while PA declines with increasing age and body mass index. Women spend more time in low-light PA, but less in MVPA than men

The New York sample spent a longer proportion of time in SB and light activities, but more time in MVPA than the country sample. Urbanicity may explain these differences

MVPA estimates vary among adults aged 60 or older, depending on the cut point chosen, and most of their time is spent in SBs

Walking, sedentary and transitory behaviours are distinct from each other, and together explain daily function

Among older adults, the steep decline in total PA occurred due to reductions in MVPA whilst light PA is relatively spared and sedentary time and long sedentary bouts increase

SB was identified as mediator for the association between obesity and falls in community living older people

Higher levels of SB in older adults were associated with reduced muscle mass and an increased risk of sarcopenia in community-dwelling older adults, independent of PA

These U.S. national data show a strong relationship between greater time spent in SB and the presence of ADL disability, independent of time spent in moderate or vigorous activity 
Table 1 continued

\begin{tabular}{|c|c|c|c|c|}
\hline $\begin{array}{l}\text { Data presented in } \\
\text { paragraph(s) }\end{array}$ & Author(s) & $\begin{array}{l}\text { Study } \\
\text { population }\end{array}$ & $\begin{array}{l}\text { Subjective or } \\
\text { objective SB } \\
\text { tool }\end{array}$ & General finding(s) \\
\hline \multirow{9}{*}{$\begin{array}{l}\text { Health impact of SB- } \\
\text { Cardio metabolic health \& } \\
\text { mortality }\end{array}$} & $\begin{array}{l}\text { Santos et al. } \\
\text { (2012) }\end{array}$ & $\mathrm{n}=312$ & Objective & $\begin{array}{l}\text { Elderly who spend more time in PA or less time in SBs } \\
\text { exhibit improved functional fitness and other confounders }\end{array}$ \\
\hline & $\begin{array}{l}\text { Chastin } \\
\text { et al. } \\
(2012)\end{array}$ & $\mathrm{n}=30$ & Objective & $\begin{array}{l}\text { The pattern of SB accumulation varies between older } \\
\text { adults and is associated with muscle quality and } \\
\text { adiposity }\end{array}$ \\
\hline & $\begin{array}{l}\text { Cawthon } \\
\text { et al. } \\
(2013)\end{array}$ & $\mathrm{n}=1983$ & Objective & $\begin{array}{l}\text { Older men with lower total energy expenditure, lower } \\
\text { moderate activity, or greater sedentary time were more } \\
\text { likely to develop a functional limitation }\end{array}$ \\
\hline & $\begin{array}{l}\text { Ensrud et al. } \\
\text { (2014) }\end{array}$ & $\mathrm{n}=2918$ & Objective & $\begin{array}{l}\text { In older men exceeding current guidelines on PA, greater } \\
\text { time spent in SB is associated with increased mortality risk }\end{array}$ \\
\hline & $\begin{array}{l}\text { Chase et al. } \\
\text { (2014) }\end{array}$ & $\mathrm{n}=54$ & Objective & $\begin{array}{l}\text { SB is associated with an adverse metabolic effect on low- } \\
\text { density lipoprotein in seniors, even those who meet } \\
\text { guideline recommendations for an active 'fit' adult }\end{array}$ \\
\hline & $\begin{array}{l}\text { Gennuso } \\
\text { et al. } \\
(2013)\end{array}$ & $\mathrm{n}=1914$ & Objective & $\begin{array}{l}\text { The results suggest that sufficient MVPA did not } \\
\text { ameliorate the negative associations between SB and } \\
\text { cardio metabolic risk factors or functional limitations } \\
\text { in the current sample }\end{array}$ \\
\hline & $\begin{array}{l}\text { Inoue et al. } \\
\quad(2012)\end{array}$ & $\mathrm{n}=1806$ & Subjective & $\begin{array}{l}\text { Spending less time watching } \mathrm{TV} \text {, a predominant } \mathrm{SB} \text {, was } \\
\text { associated with lower risk of being overweight or } \\
\text { obese, independent of meeting PA guidelines }\end{array}$ \\
\hline & $\begin{array}{l}\text { Stamatakis } \\
\text { et al. } \\
\text { (2012) }\end{array}$ & $\mathrm{n}=2765$ & Both & $\begin{array}{l}\mathrm{SB} \text { is associated with cardio metabolic risk factors, but } \\
\text { the associations are more consistent when it is } \\
\text { measured by self-report that includes TV viewing }\end{array}$ \\
\hline & $\begin{array}{l}\text { Gardiner } \\
\text { et al. } \\
(2011 \mathrm{c})\end{array}$ & $\mathrm{n}=1958$ & Subjective & $\begin{array}{l}\text { High levels of SB were associated with greater } \\
\text { prevalence of the metabolic syndrome }\end{array}$ \\
\hline
\end{tabular}

Bankoski $\mathrm{n}=1367 \quad$ Objective et al. (2011)

Gao et al. $\mathrm{n}=455 \quad$ Subjective (2007)

LeónMuñoz et al. (2013)

Pavey et al. $\mathrm{n}=6656 \quad$ Subjective (2015)

GómezCabello et al. (2012)

Health impact of SBOther (health) outcomes \& quality of Withall et al. (2014)
The proportion of sedentary time was strongly related to metabolic risk, independent of PA

A high prevalence of the metabolic syndrome in a representative sample of Caribbean-origin Hispanic elders was associated with prolonged television viewing, independent of PA and energy intake

Compared with consistently sedentary older adults, consistently non-sedentary individuals showed reduced all-cause mortality. Individuals who changed sitting time experienced an intermediate reduction in mortality

Prolonged sitting-time was positively associated with allcause mortality. Women who reported sitting for more than $8 \mathrm{~h} /$ day and did not meet PA guidelines had an increased risk of dying within the next 9 years

Sitting time increases the risk of overweight-obesity and overfat in women and the risk of central obesity in men, independently of walking time

Steps, MVPA and lower limb function were independently and moderately positively associated with perceived physical well-being but relationships with mental well-being variables were weak. No significant associations between SBs and well-being were observed 
Table 1 continued

\begin{tabular}{|c|c|c|c|c|}
\hline $\begin{array}{l}\text { Data presented in } \\
\text { paragraph(s) }\end{array}$ & Author(s) & $\begin{array}{l}\text { Study } \\
\text { population }\end{array}$ & $\begin{array}{l}\text { Subjective or } \\
\text { objective SB } \\
\text { tool }\end{array}$ & General finding(s) \\
\hline & $\begin{array}{l}\text { Balboa- } \\
\text { Castillo et al. } \\
(2011)\end{array}$ & $\mathrm{n}=1097$ & Subjective & $\begin{array}{l}\text { Greater leisure-time PA and less leisure-time SB were } \\
\text { independently associated with better long-term health- } \\
\text { related QoL in older adults }\end{array}$ \\
\hline & $\begin{array}{l}\text { Vance et al. } \\
\text { (2008) }\end{array}$ & $\mathrm{n}=158$ & Subjective & $\begin{array}{l}\text { Partial support was found for PA to improve and SB to } \\
\text { worsen cognitive health }\end{array}$ \\
\hline & $\begin{array}{l}\text { Verghese et al. } \\
\text { (2003) }\end{array}$ & $\mathrm{n}=469$ & Subjective & $\begin{array}{l}\text { Participation in certain seated leisure activities (like reading } \\
\text { or playing board games) is associated with a reduced risk } \\
\text { of dementia, even after adjustment for base-line cognitive } \\
\text { status and after the exclusion of subjects with possible } \\
\text { preclinical dementia }\end{array}$ \\
\hline \multirow[t]{13}{*}{$\begin{array}{l}\text { Strategies to } \\
\text { counteract the } \\
\text { health effects of SB }\end{array}$} & $\begin{array}{l}\text { Meneguci } \\
\text { et al. (2015) }\end{array}$ & $\mathrm{n}=3296$ & Subjective & $\begin{array}{l}\text { Socio-demographic, clinical, and health behaviour factors } \\
\text { are associated with high sitting time in older adults from } \\
\text { South-eastern Brazil }\end{array}$ \\
\hline & $\begin{array}{l}\text { Sardinha et al. } \\
\text { (2015) }\end{array}$ & $\mathrm{n}=215$ & Objective & $\begin{array}{l}\text { Breaking-up sedentary time is associated with better } \\
\text { physical function in older adults; and, it may have an } \\
\text { important place in future guidelines on preserving older } \\
\text { adults' physical function to support ADL }\end{array}$ \\
\hline & $\begin{array}{l}\text { Gardner et al. } \\
\text { (2014) }\end{array}$ & $\mathrm{n}=120$ & Both & $\mathrm{N} / \mathrm{a}$ \\
\hline & $\begin{array}{l}\text { Chastin et al. } \\
\text { (2014b) }\end{array}$ & $\mathrm{n}=11$ & Subjective & $\begin{array}{l}\text { Older adults consider self-efficacy, functional limitations, } \\
\text { ageist stereotyping, locus of control, and pain as } \\
\text { determinants of their SB }\end{array}$ \\
\hline & $\begin{array}{l}\text { van der Berg } \\
\text { et al. (2014) }\end{array}$ & $\mathrm{n}=565$ & Objective & $\begin{array}{l}\text { Some demographic, socioeconomic, and biomedical } \\
\text { determinants in midlife were associated with considerably } \\
\text { more sedentary time per day in old age }\end{array}$ \\
\hline & $\begin{array}{l}\text { Van } \\
\text { Cauwenberg } \\
\text { et al. (2014a) }\end{array}$ & $\mathrm{n}=50,986$ & Subjective & $\begin{array}{l}\text { There is a cross-sectional link between older adults' } \\
\text { television viewing time and social composition of their } \\
\text { neighbourhood, formal participation, access to alternative } \\
\text { activities, and safety from crime }\end{array}$ \\
\hline & $\begin{array}{l}\text { Fitzsimons } \\
\text { et al. (2013) }\end{array}$ & $\mathrm{n}=24$ & Both & $\begin{array}{l}\text { A consultation approach may help individuals reduce time } \\
\text { spent in SBs }\end{array}$ \\
\hline & $\begin{array}{l}\text { Davis et al. } \\
\quad(2014)\end{array}$ & $\mathrm{n}=217$ & Objective & $\begin{array}{l}\text { Promoting regular breaks in sedentary time might be useful } \\
\text { in maintaining or increasing lower extremity function and } \\
\text { later life independence }\end{array}$ \\
\hline & $\begin{array}{l}\text { Kikuchi et al. } \\
\text { (2013) }\end{array}$ & $\mathrm{n}=1665$ & Subjective & $\begin{array}{l}\text { Particular socio-demographic and behavioural } \\
\text { characteristics related to TV time among Japanese older } \\
\text { adults have been identified, but they differ by gender }\end{array}$ \\
\hline & $\begin{array}{l}\text { Gardiner et al. } \\
\text { (2011b) }\end{array}$ & $\mathrm{n}=59$ & Objective & $\begin{array}{l}\text { Sedentary time in older adults can be reduced following a } \\
\text { brief intervention based on goal setting and behavioural } \\
\text { self-monitoring }\end{array}$ \\
\hline & $\begin{array}{l}\text { Nicklas et al. } \\
\text { (2014) }\end{array}$ & $\mathrm{n}=48$ & Objective & $\begin{array}{l}\text { Self-monitoring of spontaneous PA and SB enhanced } \\
\text { successful maintenance of lost weight }\end{array}$ \\
\hline & $\begin{array}{l}\text { Uffelen et al. } \\
\text { (2012) }\end{array}$ & $\mathrm{n}=6116$ & Subjective & $\begin{array}{l}\text { It is suggested that older women with a high health risk } \\
\text { profile and social risk profile may particularly benefit } \\
\text { from interventions to promote both reducing sitting time } \\
\text { and increasing PA or at least light activities }\end{array}$ \\
\hline & $\begin{array}{l}\text { Dogra and } \\
\text { Stathokostas } \\
(2014)\end{array}$ & $\mathrm{n}=14,560$ & Subjective & $\begin{array}{l}\text { Several specific correlates of extended sitting time were } \\
\text { identified; these findings have implications for public } \\
\text { health strategies targeting older adults }\end{array}$ \\
\hline
\end{tabular}


Table 1 continued

\begin{tabular}{|c|c|c|c|c|}
\hline $\begin{array}{l}\text { Data presented in } \\
\text { paragraph }(\mathrm{s})\end{array}$ & Author(s) & $\begin{array}{l}\text { Study } \\
\text { population }\end{array}$ & $\begin{array}{l}\text { Subjective or } \\
\text { objective SB tool }\end{array}$ & General finding(s) \\
\hline \multicolumn{5}{|l|}{ Reviews } \\
\hline \multirow[t]{2}{*}{$\begin{array}{l}\text { Prevalence and } \\
\text { types of SB }\end{array}$} & $\begin{array}{l}\text { Harvey et al. } \\
\text { (2013) }\end{array}$ & $\mathrm{n}=372,550$ & Both & $\begin{array}{l}\text { Whether measurements are subjective or objective, the } \\
\text { majority of older adults are sedentary }\end{array}$ \\
\hline & $\begin{array}{l}\text { Harvey et al. } \\
\quad(2015)\end{array}$ & $\mathrm{n}=349,698$ & Both & $\begin{array}{l}\text { Time spent sedentary ranges from } 5.3 \text { to } 9.4 \mathrm{~h} \text { per } \\
\text { waking day in older adults }\end{array}$ \\
\hline $\begin{array}{l}\text { Health impact of } \\
\text { SB-Overall }\end{array}$ & $\begin{array}{l}\text { de Rezende } \\
\text { et al. (2014a) }\end{array}$ & $\mathrm{n}=335,503$ & Both & $\begin{array}{l}\text { The data supports the relationship between SB and } \\
\text { mortality in older adults }\end{array}$ \\
\hline
\end{tabular}

$S B$ sedentary behaviour, $C H A M P S$ community healthy activities model program for seniors, $M V P A$ moderate-to-vigorous physical activity, $P A$ physical activity, $A D L$ activities of daily living, $T V$ television, $Q o L$ quality of life, $N / a$ not applicable

accelerometers are expensive ( $\geq £ 190$ per unit), there is potential bias due to a Hawthorne effect (behaviour change in response to the awareness of being observed) and data-analysis is labour-intensive (Visser and Koster 2013; Pedišić and Bauman 2015), at least until an analysis template has been created. However, accelerometry enables more robust, objective, ambulatory and long-term recording of acceleration signals (Chastin and Granat 2010; Tremblay et al. 2010), and provides outcomes, such as total SB time, sedentary bout time, sedentary pattern, and number and frequency of breaks in SB. Nonetheless, accelerometry only addresses the energetic ontology of the definition of SB and there is no consensus on a standardised method for accelerometer data processing and analysis (e.g. non-validated cut-points or epoch lengths) (Gorman et al. 2014; Pedišić and Bauman 2015). Assumptions are still required to quantify accelerometry-based PA and SB in older adults, resulting in a potential danger of misinterpretation (Evenson et al. 2012; Kowalski et al. 2012; Gorman et al. 2014; Kozey Keadle et al. 2014). With modern technological advances, accelerometer use is assumed to be more straightforward and easy to implement. Furthermore, the possibilities of objective SB monitoring will continue to increase and provide an ever more-detailed and accurate objective picture of SB in elderly.

The main reason for preferring accelerometry in SB measurement is that it provides an objective assessment of SB and may thereby help to understand how SB is related to healthy ageing (Visser and Koster 2013; Van Cauwenberg et al. 2014b). Nevertheless, accelerometers should not substitute but supplement questionnaires (Pedišić and Bauman 2015). Selfreports are still needed to assess engagement in specific SBs and provide more detailed (qualitative) information that cannot be obtained with accelerometers (Rhodes et al. 2012; Lohne-Seiler et al. 2014; Van Cauwenberg et al. 2014b). Generally, it is suggested that SB associations are complex to interpret because they depend on the type of SB studied and the measurement method used (Table 2) (Stamatakis et al. 2012; de Rezende et al. 2014b). For example, Lenz (2014) noted that in older adults TV viewing had more associations with cardio metabolic outcomes than reports of total SB, while Celis-Morales et al. (2012) concluded that, due to underestimation, selfreports might miss some significant trends that will be found when objective assessments are used.

When capturing SB in older adults, different parameters have to be taken into account, depending on the method applied, i.e. mounting position, data filtering and algorithm, and type of device and/or questionnaire used. Additionally, potential confounders like age, gender, health status or socioeconomic status have to be considered. Another important consideration to accurately estimate SB is the number of complete data acquisition days needed. Compared with PA, more monitoring days are needed to reliably estimate SB because it is less predictable on a daily basis (Hart et al. 2011). In older adults, 5 monitoring days are required to provide a reliable $(\mathrm{ICC}=0.80$ ) SB estimate when using an objective method, while only 3 days are necessary to monitor PA with the same level of reliability (Hart et al. 2011). Increasing the number of monitoring days to either 7,11 or 21 , will improve the reliability of SB monitoring resulting in ICCs of $0.85,0.90$ and 0.95 respectively (Hart et al. 2011). Since studies are divergent on whether there is a difference in SB between week and weekend days in older adults, it is advised to include both when using a 


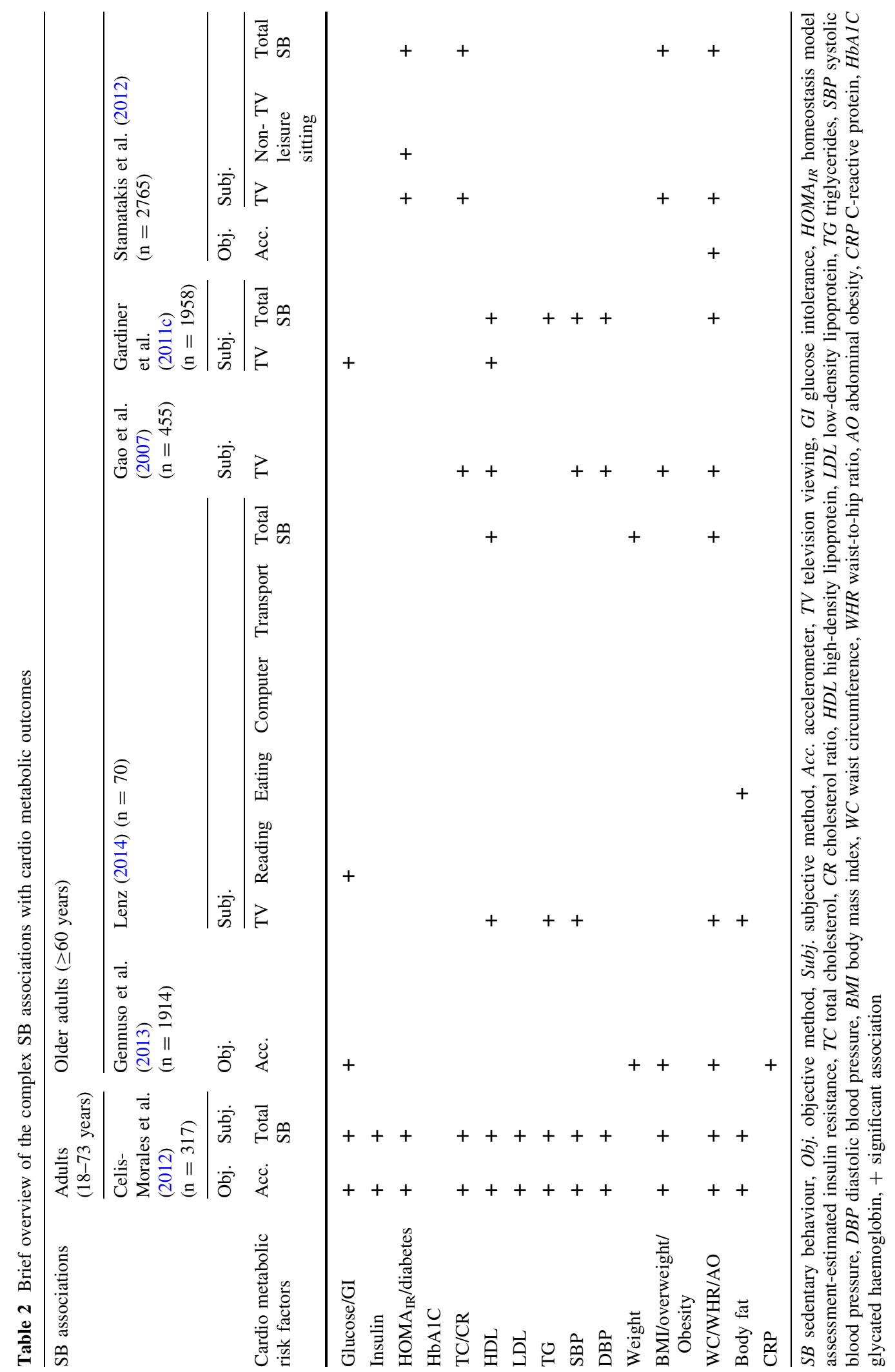


$<7$-day monitoring protocol (Hart et al. 2011; Davis et al. 2011; Visser and Koster 2013). Compared to objective methods, self-reports show larger day-today differences and therefore they require more monitoring days (preferably $\geq 7$ ) to reliably predict SB (Hart et al. 2011).

Generally, SB assessment in older adults is challenging, regardless of the method applied or outcome measures used. A combination of both objective (using postural allocation) and self-reported methods used in a 7-day monitoring protocol is currently suggested to be optimal for assessing SB in older adults.

\section{Prevalence and types of sedentary behaviour}

Daily function in older adults is mainly subdivided in walking, postural transitions and SB (Lord et al. 2011), with several studies reporting that most of their time is spent in SBs (Healy et al. 2008; Davis et al. 2011; Evenson et al. 2012; Shiroma et al. 2013; Jefferis et al. 2015b). Previous literature shows that SB increases with age, resulting in older adults (aged $\geq 60$ years) being the most sedentary (Matthews et al. 2008; Rhodes et al. 2012; Martin et al. 2014) and old-older adults being more sedentary than young-older adults (Table 3) (Evenson et al. 2012; Martin et al. 2014; Harvey et al. 2015). Interestingly, after retirement (from $\sim 65$ years of age) the amount of SB transiently reduces, while the percentage of ambulatory activity increases (Godfrey et al. 2014). Not only the amount of SB and long sedentary bouts increase with ageing in older adults, but also the decline in total daily PA accelerates (Table 3) (Davis et al. 2011; Harvey et al. 2013; Buchman et al. 2014; Martin et al. 2014;
Jefferis et al. 2015a). This latter decline is characterized by: (1) lower PA volume, (2) less higher-intensity PA, and (3) lower frequency of getting out and about (Davis et al. 2011). This results in old-older adults (aged $\geq 85$ years) performing only one third of the activity performed by young-older adults (aged 70-74.9 years) at peak activity times (Davis et al. 2011).

According to national surveys, adults are on average sedentary for $8 \mathrm{~h}$ of the waking day, and this figure rises to $>10 \mathrm{~h}$ in older adults (Matthews et al. 2008; Davis et al. 2011; Lenz 2014). However, two systematic reviews describe that self-reported SB in older adults (aged $\geq 60$ years) is on average $5.3 \mathrm{~h}$ /day only (Harvey et al. 2015), with $\sim 60 \%$ reporting sitting $>4 \mathrm{~h}$ /day during waking hours (Harvey et al. 2013). When using objective measurements, older adults (aged $\geq 60$ years) spend on average 8.5-9.6 h/day sedentary (Evenson et al. 2012, 2014; Harvey et al. 2015), which equals $65-80 \%$ of their waking day. Other accelerometer-based studies showed that older adults spend approximately $75-80 \%$ of their awake time in SB which represents 8-12 h/day (Arnardottir et al. 2013; de Rezende et al. 2014a). Other studies suggest that $67 \%$ of the older age population is sedentary for $>8.5 \mathrm{~h}$ /day (Stamatakis et al. 2012), and that about half (47\%) of them are sedentary $>80 \%$ of their waking hours (Davis et al. 2011). In general, older adult men spend more time in SB ( $\sim 75 \%$ of the day) than older adult women ( $\sim 66 \%$ of the day), but in both the total time of SB is primarily the result of accumulation of many relatively short SB bouts of less than $30 \mathrm{~min}$ (Davis et al. 2011; Evenson et al. 2012; Shiroma et al. 2013; Harvey et al. 2015; Jefferis et al. 2015b).
Table 3 Comparison of accelerometer-derived SB across different age groups

Values represent mean hours/day adjusted for monitor-wearing time $S B$ sedentary behaviour

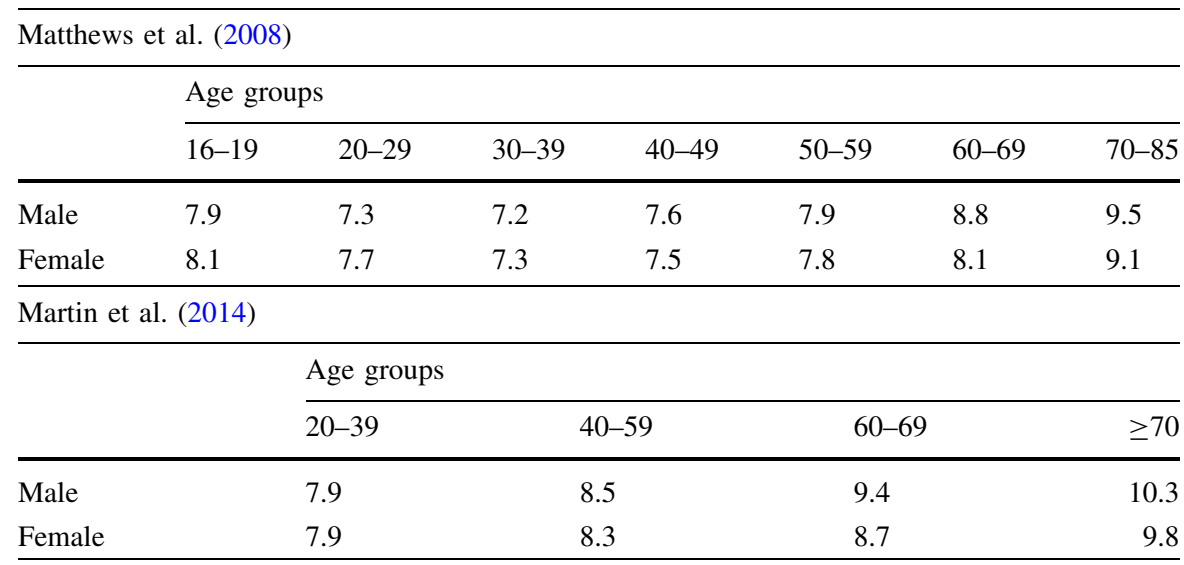


For a better and more detailed understanding of SB, it is important to assess typical SBs. Previous research has shown that older adults engage in approximately 16 types of SB daily, with TV viewing, reading, eating meals, computer use and transportation being the most common (Lenz 2014). Generally, TV viewing and computer use are the main SB measures, followed by the overall assessment of time-spent sitting (van Uffelen et al. 2011; Rhodes et al. 2012; Visser and Koster 2013). Time spent TV viewing combined with computer use is termed screen time (Harvey et al. 2013). About $53 \%$ of the older adults report daily screen time $>4 \mathrm{~h}$, and $\sim 94 \%>2 \mathrm{~h}$ (Harvey et al. 2013). When splitting daily screen time, older adults watch on average $3.3 \mathrm{~h} \mathrm{TV}$, with more than half of the age group (54\%) sitting in front of the TV for $3 \mathrm{~h}$, while about one third watches TV $>3.6 \mathrm{~h}$ and $15 \%$ $>4$ h daily (Harvey et al. 2013). Around $65 \%$ of older adults use computers, but $<10 \%$ use it more than $1.6 \mathrm{~h}$ daily (Harvey et al. 2013). A more general outcome, like leisure sitting time (excluding TV time), is reported by older adults to be on average $3.3 \mathrm{~h}$ daily, and reported by $\sim 54 \%$ to be $>3 \mathrm{~h}$ (Patel et al. 2010; Harvey et al. 2015). Total sitting time $>3 \mathrm{~h}$ is reported in older adults by $78 \%$, with $\sim 59 \%$ reporting sitting $>4 \mathrm{~h}, \sim 27 \%$ reporting $>6 \mathrm{~h}$ and $5 \%$ reporting $>10$ h daily (Harvey et al. 2013).

Although the amount of SB varies in the current literature depending on the assessment method used (range 5.3-12 h/day), it is nevertheless clear that SB is highly prevalent in older adults. PA appears to be lower and of less intensity, making light-intensity PA (LIPA) the most common type of PA within the oldest age groups (Table 3 ). This suggests that LIPA is the most feasible PA in elderly, which is of interest to counteract $\mathrm{SB}$, as will be discussed later.

\section{Sedentary physiology}

Research into the physiology and health impacts of SB has recently increased and represents an exciting new field of study, which is distinct but complementary to exercise physiology, namely sedentary physiology (Tremblay et al. 2010; Sedentary Behaviour Research Network 2012; Dunstan et al. 2012a). Associations between SB and several outcomes have been reported. However, the mechanisms underlying the association between SB and adverse health effects remain uncertain and are therefore a research priority (Dunstan et al. 2012a; Gianoudis et al. 2015). To date, physiological mechanisms for four different outcomes have been proposed regardless of age, namely:

- Cardio metabolic It has been proposed that reduced energy expenditure and muscle contractions not only lead to reduced insulin sensitivity and an increase in pro-inflammatory cytokines (Tremblay et al. 2010; Yates et al. 2012), but also decreased lipoprotein lipase (LPL) activity and muscle glucose transporter (GLUT) protein content (Tremblay et al. 2010; Gianoudis et al. 2015);

- Vascular Studies have shown that shear rate, FMD and brachial artery diameter decrease, while endothelial cell damage and blood pressure increase with increasing SB (Demiot et al. 2007; Hamburg et al. 2007; Thosar et al. 2015);

- Muscle-tendon It is proposed that continual underloading due to SB, negatively affects muscletendon properties, since muscle-tendon disuse causes changes (e.g. muscle atrophy and increased tendon compliance). Aside from that, $\mathrm{SB}$ is thought to be a determinant driver for obesity (Chastin et al. 2012). Generally, it is proposed that an increase in visceral and intermuscular fat stimulates the release of pro-inflammatory cytokines and decrease of anti-inflammatory markers from adipose tissue, having a catabolic effect on muscle tissue by impairing muscle protein synthesis (Gianoudis et al. 2015). This will affect muscle performance, however that does not only arise from muscular but also neural factors (Tomlinson et al. 2014);

- Skeletal SB is thought to change the balance between bone resorption and deposition, mainly by a rapid increase in bone resorption (marked by increased deoxypyridinoline, urinary calcium and type I collagen cross-linked N-telopeptides) without concomitant changes in bone formation, resulting in reduced bone mineral content and increased risk of osteoporosis (Kim et al. 2003; Tremblay et al. 2010).

\section{Health impact of sedentary behaviour}

Despite a high prevalence, SB in older adults has so far received limited scientific attention (Gennuso et al. 


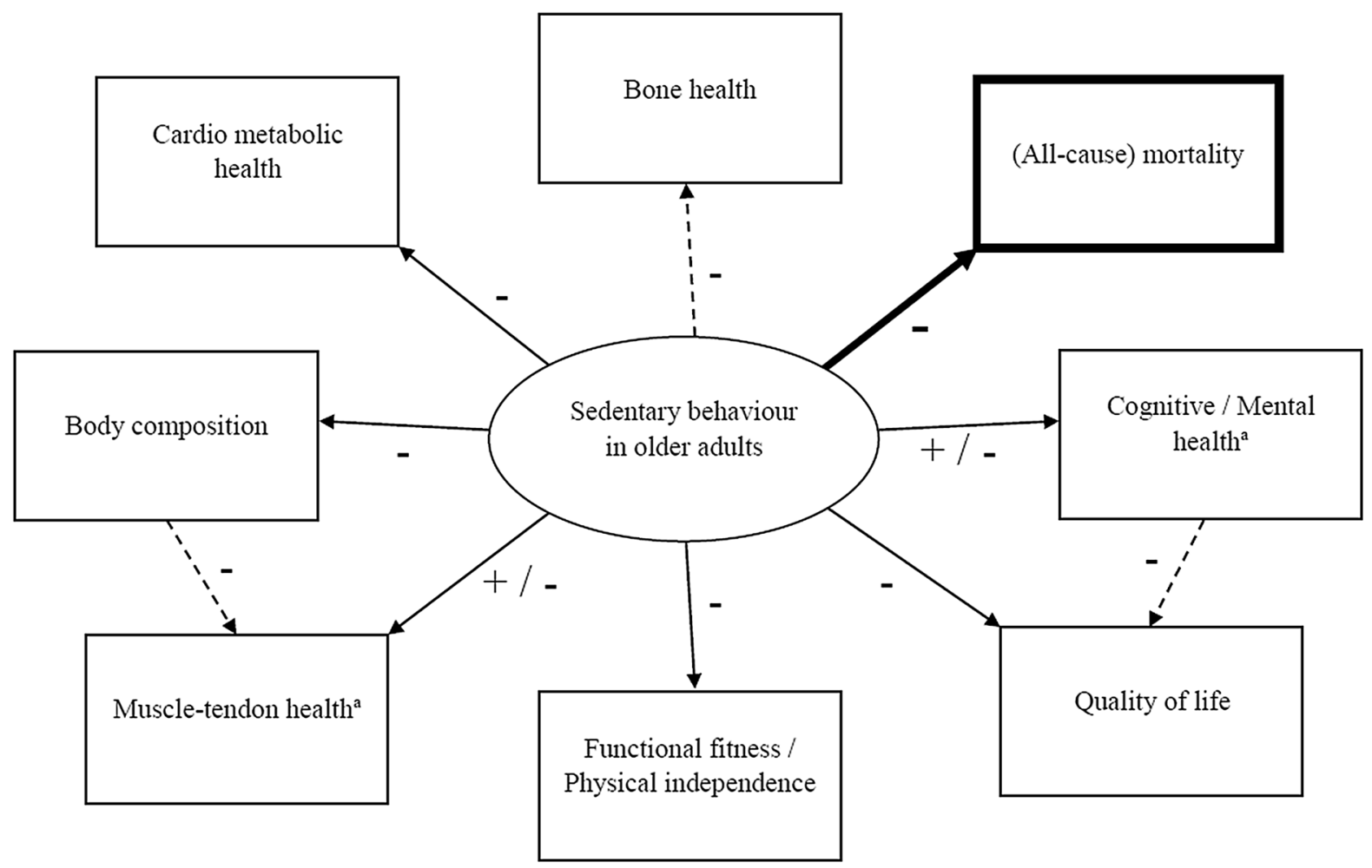

Fig. 2 Overview of identified and suggested associations between SB and (health) outcomes in older adults as reported in literature + positive association; - negative association; solid lines represent identified associations; dashed lines represent

2013; Van Cauwenberg et al. 2014b). A general overview of reported (health) outcomes, independently associated with SB in healthy, communitydwelling older adults, is provided below (Fig. 2).

Musculoskeletal health \& functional fitness

Although proof of SB effects on musculoskeletal health is limited in elderly, some interesting findings have been reported. Evidence shows for example, that associations between screen-based SB and muscle strength, independently of PA, are context-specific where TV viewing is associated with lower muscle strength while opposite effects are observed for computer use (Hamer and Stamatakis 2013). This might result from lower energy expenditure and unhealthier eating behaviours during TV watching, but also a potential confounding effect of education level on computer use (Visser and Koster 2013; Lenz 2014). Further, a study examining the relation between sarcopenia and SB, showed that higher volumes of TV suggested associations; Associations in bold are confirmed by a systematic review from de Rezende et al. (2014a). ${ }^{\text {a Outcome }}$ depends on the type of assessed SB (e.g. TV viewing, computer use or reading)

viewing time were related to lower total body and leg lean mass after adjusting for fat mass, which was positively associated with the duration of watching TV (Gianoudis et al. 2015). Another study confirmed this latter finding by suggesting that SB is directly related to (lower limb) adiposity in older men, but increased and prolonged SB was also, unexpectedly, associated with increased leg power and muscle quality in these men (Chastin et al. 2012). Possible explanations for this latter finding were, e.g. carrying more body fat may provide a training stimulus or results reflect adiposity developing in previously strong men who have recently become sedentary. However, according to Chastin et al. (2012), their results should be interpreted with caution since the study sample was not necessarily representative of elderly in general. Other research shows that higher levels of SB in older adults are associated with an increased risk of sarcopenia and limited physical function, independent of PA or other potential confounding factors (Gennuso et al. 2013; Gianoudis et al. 2015). These findings are 
confirmed by other studies showing that even after adjusting for PA and other confounders, objectively measured SB is negatively associated with functional fitness and the ability to perform activities of daily living (Santos et al. 2012; Cawthon et al. 2013; Dunlop et al. 2015). According to Marques et al. (2014), SB is only a predictor for the risk of losing physical independence when not controlling for PA intensities. However, this finding might result from misclassification of participants due to using accelerometer data of less than five monitoring days and a self-reported measure of physical function. Santos et al. (2012) found that PA was positively related to functional fitness, independent of SB, and therefore they concluded that both SB reduction and PA increase in older adults might preserve functional fitness and performance in terms of daily functioning tasks and independent living. Especially obese people could benefit from this since SB has been identified as a mediator for the association between obesity and falls in elderly (Mitchell et al. 2015). A study on successful ageing, which represents the physical, psychosocial, and social success with which adults age, showed that SB is associated with lower odds of successful ageing (Dogra and Stathokostas 2012). Although a dosedependent relationship exists between SB and each of the three successful ageing components, the strongest association was found between SB and functional limitations (physical component) (Dogra and Stathokostas 2012). Functional dependence in old age is more likely to develop in older adults who are not physically active, or who were not so during their middle age (Dogra and Stathokostas 2012; Marques et al. 2014).

Skeletal measures are limited to a single report, showing that independent of time spent engaging in $\mathrm{PA}, \mathrm{SB}$ is negatively associated with femur bone mineral density in older women only (Chastin et al. 2014c).

\section{Cardio metabolic health \& mortality}

Regarding risk factors for cardio metabolic diseases, TV viewing and self-reported SB are positively associated with (i) dyslipidaemia characterised by increased triglycerides and lower high-density lipoprotein (HDL), (ii) obesity, (iii) hypertension and (iv) glucose intolerance (in women only) (Gao et al. 2007; Gardiner et al. 2011c; Inoue et al. 2012; Lenz
2014). These findings are in agreement with another study suggesting that self-reported SB (TV viewing in particular) and, to a lesser extent, objectively measured SB in older adults are negatively associated with two cardio metabolic risk proxies, independently of PA: (1) cholesterol index and (2) diabetes prevalence (Stamatakis et al. 2012). Gennuso et al. (2013) also reported that associations between accelerometerderived SB and various health outcomes in older adults were not modified by PA, however they only found independent associations with body mass (index), waist circumference, C-reactive protein and plasma glucose, but not with blood pressure, cholesterol markers and triglycerides (Gennuso et al. 2013). Nevertheless, Chase et al. (2014) showed that objectively measured SB was associated with an adverse metabolic effect on low-density lipoprotein (LDL) levels in physically active elderly. Overall, most studies suggest that watching TV and/or engaging in large amounts of total SB is negatively associated with the (cardio metabolic) health of older adults (Bankoski et al. 2011; Gardiner et al. 2011c; Gómez-Cabello et al. 2012; Lenz 2014). Moreover, SB also negatively affects mortality independently of PA, either or not caused by cardio metabolic disorders (Dogra and Stathokostas 2012; Stamatakis et al. 2012; MartínezGómez et al. 2013; León-Muñoz et al. 2013; Ensrud et al. 2014; Pavey et al. 2015).

Other (health) outcomes \& quality of life (QoL)

Although Withall et al. (2014) did not find an association between SB and subjective well-being of older adults, evidence shows that in the elderly, less leisure-time SB is independently associated with better long-term health-related QoL and cognitive performance (Balboa-Castillo et al. 2011; Steinberg et al. 2015). The number of sitting hours were inversely related with the scale scores of physical functioning, physical role, bodily pain, vitality, social functioning and mental health (Balboa-Castillo et al. 2011). Obesity, diabetes and hypertension are possible mediating mechanisms for these associations between SB and well-being (Balboa-Castillo et al. 2011). As stated earlier in this review, leisure-time SB types are differently associated with health markers in older adults (Kesse-Guyot et al. 2012; Kikuchi et al. 2014). For example, higher passive SB (e.g. TV viewing) is associated with a higher likelihood of being 
overweight, adverse health behaviours (like poor diet) and greater psychological distress, while mentallyactive sedentary time (i.e. reading or computer use) is not associated with health-related attributes and may involve (i) beneficial processes which prevent for the deleterious impact of sitting in older adults, (ii) provide mental stimulation improving cognitive performance capacities and (iii) improve social interaction and QoL (Verghese et al. 2003; Vance et al. 2008; Kesse-Guyot et al. 2012; Visser and Koster 2013; Kikuchi et al. 2014). Overall across age groups, most sedentary activities are suggested to decrease communication with family, reduce the social network and increase the risk of depression, anxiety and stress, which would explain the poorer QoL associated with SB (Balboa-Castillo et al. 2011).

In spite of the limited number of SB studies in older adults, evidence is growing on the (in general) adverse health effects of SB. A recent systematic review by de Rezende et al. (2014a), accounting for the quality of SB studies in older adults (assessed with the Grades of Recommendation, Assessment, Development and Evaluation (GRADE) tool), suggests, however, that to date evidence is inconclusive. Due to the limited quality of available studies, only scarce evidence exists for all the reported health outcomes associated with SB in elderly, except for the evidence on a previously established dose-response relationship between SB and all-cause mortality, which was confirmed (Fig. 2) (de Rezende et al. 2014a). Moreover, the evidence on musculoskeletal health and functional fitness in relation to SB in elderly, has not been graded by de Rezende et al. (2014a). Overall, the present evidence of independent associations between SB and health outcomes in older adults should be carefully interpreted, and further research, to either support or refute the current findings, is needed to draw firm conclusions which will lead to informed SBminimisation strategies and guidelines for older adults (de Rezende et al. 2014a).

\section{Strategies to counteract the health effects of sedentary behaviour}

Regardless of the inconclusive evidence on all of the possible negative health effects of SB in older adults, multiple studies have already proposed strategies to counteract the health impact of SB. These strategies can be classified as either interventional or preventative.

Generally, research shows that especially prolonged sedentary bouts instead of frequent sedentary bouts, have negative health effects, and therefore sitting duration should be focused on more than on frequency (Bond et al. 2014; Chastin et al. 2014c). To date, several studies on different age groups (including older adults) have already shown that breaking prolonged sedentary bouts can be effective, particularly in decreasing the cardio metabolic disease risk (Healy et al. 2008; Bankoski et al. 2011; Bond et al. 2014; Gianoudis et al. 2015; Bailey and Locke 2015), while results on musculoskeletal health and function appear to be equivocal (Gianoudis et al. 2015). Nevertheless, both Sardinha et al. (2015) and Davis et al. (2014) found an association between breaks in SB and better physical function in older adults. Although all these findings make breaking prolonged SB a very promising intervention, it has not been studied as such in elderly yet and, only few studies have been conducted to promote adoption of this approach overall (Bond et al. 2014). In general, it is not necessary to decrease SB dramatically before any health effect can be achieved. This was shown by Pronk et al. (2012), who noted that only $16 \%$ decrease in SB already generated health benefits in employees with sedentary jobs. Other non-elderly studies reported improved cardio metabolic factors in participants breaking every 20-30 min of sitting with just $\sim 2$ min of PA (Dunstan et al. 2012b; Peddie et al. 2013; Bailey and Locke 2015). These results are highly stimulating in counteracting SB, since it is a habitual lifestyle and therefore difficult to change (Hart et al. 2011; Bond et al. 2014).

It appears that the intensity of the SB interruption is an important factor regarding its health effect (Chastin et al. 2012; Bailey and Locke 2015). Bailey and Locke (2015) showed that interrupting sitting with standing alone is not sufficient and that at least LIPA (e.g. lightintense walking) is required. A possible explanation is that minor increases in contractile activity (which are associated and easily achieved with LIPA) can dramatically increase muscle GLUT-1 \& 4 content and glucose tolerance in sedentary individuals (Tremblay et al. 2010; Latouche et al. 2013; Sardinha et al. 2015). This is ideal, since LIPA is not only inversely related with $\mathrm{SB}$, but also a feasible approach for older adults to increase total PA and ameliorate the 
deleterious health effects of SB (Hamilton et al. 2008; Healy et al. 2011). However, it needs to be determined if there might be any adverse consequences of shifting SB into LIPA, especially in case of older adults who may be more prone to lower-body musculoskeletal problems (Tremblay et al. 2010). Changing SB to moderate-to-vigorous PA (MVPA) (e.g. brisk walking, walking stairs or exercising) would potentially lead to spontaneous compensatory behaviour resulting in a less fragmented and possibly, higher total SB in turn, and is therefore not preferred (Chastin et al. 2012). Epidemiologic evidence suggests that having a positive balance between LIPA and SB is desirable due to the inverse linearity of LIPA with a number of cardio metabolic biomarkers (Hamilton et al. 2008). It is known that physiological responses and adaptations may differ within and between physiological systems (Tremblay et al. 2010). For sedentary people it is suggested that LIPA might only have beneficial effects on the cardiovascular and metabolic systems, but not on the musculoskeletal system possibly due to a lack of overload, which is normally required for improvement of this particular system. Results from a preliminary study support this and suggest that vigorous PA during breaks is associated with higher muscle quality in older adults (Chastin et al. 2012). However, new evidence from a small study in young males (mildly active only i.e. not involved in any type of exercise program and not having undergone a systematic resistance training program within 1 year prior onset of the intervention) indicates that also mild walking can improve muscle strength (Maeo et al. 2015). Nevertheless, small changes from SB to LIPA can already lead to a decrease in risk for chronic diseases and mortality (Tremblay et al. 2010). Moreover, these small changes also increase physical functioning which reduces the risk of falls, allowing older adults to live independently and enhance the quality of later life (Sardinha et al. 2015). These advantages are not necessarily associated with MVPA and do also not require prolonged periods of PA (Sardinha et al. 2015). However, regular MVPA is still important in the prevention and treatment of chronic diseases, even in older adults (Dunstan et al. 2012a). Therefore, both PA and SB should be part of general guidelines, but more studies are needed to create informed guidelines for SB in the elderly (de Rezende et al. 2014a). In addition to breaking prolonged SB and reducing total $\mathrm{SB}$, studies have also reported that specific, primarily passive SB (e.g. TV watching) should be targeted, since this type of SB is also related to other adverse health behaviours, like poor diet (Visser and Koster 2013). Overall, no definitive recommendations regarding the maximum total $\mathrm{SB}$, number and duration of breaks, and optimal interventional strategy to stimulate breaking prolonged SB exists currently, as it requires more research (Dunstan et al. 2012a).

Regardless of this, as well as motivational interviewing (which was successful in stimulating PA in elderly (Letourneau and Goodman 2014), as the emerging use of technology might be promising tools to stimulate and alert breaks in SB. A recent example of the latter method is a study by Bond et al. (2014) who successfully used smartphone and activity monitor applications that provide personal feedback and prompt frequent short sitting breaks based on real-time data. However, their study was performed on a middle-aged population, so it is unclear whether this will also be effective in older adults, but expectations are high. Although interventions might be successful in the short-term, future research is necessary to examine also the long-term post-intervention effects on the amount and pattern of SB and PA. In order to design successful intervention programs it is important to know what reasons (apart from health or age) older adults might have that make them (more) sedentary or stay inside, such as social, economic and environmental factors (Uffelen et al. 2012; Kikuchi et al. 2013; Van Cauwenberg et al. 2014a; Dogra and Stathokostas 2014; Meneguci et al. 2015). A preliminary study by Chastin et al. (2014b) reported some specific factors, considered as determinants of SB by older adults themselves, like self-efficacy, functional limitations, ageist stereotyping, locus of control (the extent to which people believe they have personal control over events and outcomes in their lives), and pain. Considering these factors when designing SBreducing interventions, might presumably lead to tailored strategies with high efficacy (Chastin et al. 2014b). Other characteristics of successful intervention programs to reduce SB in older adults might include personalised goal setting and feedback as part of behavioural self-monitoring using a consultation approach (Gardiner et al. 2011b; Fitzsimons et al. 2013). Something like this was already proven successful in preventing weight regain in elderly (Nicklas et al. 2014). Or maybe even some form of reinforcement or habit formation like in a newly 'On 
Your Feet to Earn Your Seat' randomized controlled trial (Gardner et al. 2014).

Instead of interventions, it might also be useful to see whether large amounts of (prolonged) SB can be prevented in elderly. Therefore, it is important to gain knowledge about the risk factors of SB. Previous research has shown that demographic, socioeconomic and biomedical variables in midlife (e.g. not being married, primary education, living in a duplex or living in an apartment (vs. villa), being obese, and having a heart disease) were associated with a higher prevalence of SB in older age, and thus might be useful to predict which people will be highly sedentary as an older adult (van der Berg et al. 2014). This will potentially lead to prevention programs, targeted at those people identified, and might reduce SB prevalence in older adults.

Although all the suggestions for both intervention and prevention strategies may have potential, most of them are based on preliminary data only and thus need further investigation to increase evidence and generalizability.

\section{Conclusion}

Based on this review, it can be concluded that older adults are the most sedentary age group, with an accelerometer-derived average daily sitting time of 8.5-9.6 h, representing 65-80\% of their waking time. Although the literature reports negative associations of SB in elderly with outcomes such as less favourable cardio metabolic health, musculoskeletal health, body composition, physical functioning, mental health and QoL, evidence so far is inconclusive apart from the evidence on the adverse effect of SB on the all-cause mortality rate. Prevention of prolonged SB by frequent breaks, while doing at least LIPA, is a promising strategy to counteract adverse health effects. Even though it has not been studied as an intervention in older adults yet, it is expected to be effective on this age group too. This is not only because LIPA appears to be the most common type of PA within the oldest age groups, but also due to the availability of advanced technology. Overall, more studies in elderly are required to increase the evidence level and develop informed SB guidelines including an optimal strategy to counteract SB and its health effects. Nevertheless, the current evidence allows advising and encouraging elderly to limit their SB, as described in the latest physical activity guidelines.

Open Access This article is distributed under the terms of the Creative Commons Attribution 4.0 International License (http:// creativecommons.org/licenses/by/4.0/), which permits unrestricted use, distribution, and reproduction in any medium, provided you give appropriate credit to the original author(s) and the source, provide a link to the Creative Commons license, and indicate if changes were made.

\section{References}

Aguilar-Farías N, Brown WJ, Peeters GMEEG (2014) ActiGraph GT3X+ cut-points for identifying sedentary behaviour in older adults in free-living environments. J Sci Med Sport 17:293-299. doi:10.1016/j.jsams.2013.07.002

Aguilar-Farías N, Brown WJ, Olds TS, Geeske Peeters GMEE (2015) Validity of self-report methods for measuring sedentary behaviour in older adults. J Sci Med Sport 18:662-666. doi:10.1016/j.jsams.2014.08.004

Arnardottir NY, Koster A, Van Domelen DR et al (2013) Objective measurements of daily physical activity patterns and sedentary behaviour in older adults: age, gene/environment susceptibility-Reykjavik study. Age Ageing 42:222-229. doi:10.1093/ageing/afs 160

Bailey DP, Locke CD (2015) Breaking up prolonged sitting with light-intensity walking improves postprandial glycemia, but breaking up sitting with standing does not. J Sci Med Sport 18:294-298. doi:10.1016/j.jsams.2014.03.008

Balboa-Castillo T, León-Muñoz LM, Graciani A et al (2011) Longitudinal association of physical activity and sedentary behavior during leisure time with health-related quality of life in community-dwelling older adults. Health Qual Life Outcomes 9:47. doi:10.1186/1477-7525-9-47

Bankoski A, Harris TB, McClain JJ et al (2011) Sedentary activity associated with metabolic syndrome independent of physical activity. Diabetes Care 34:497-503. doi:10. 2337/dc10-0987

Bond DS, Thomas JG, Raynor H et al (2014) B-MOBILE-a smartphone-based intervention to reduce sedentary time in overweight/obese individuals: a within-subjects experimental trial. PLoS One 9:e100821. doi:10.1371/journal. pone. 0100821

Buchman AS, Wilson RS, Yu L et al (2014) Total daily activity declines more rapidly with increasing age in older adults. Arch Gerontol Geriatr 58:74-79. doi:10.1016/j.archger. 2013.08.001

Busschaert C, De Bourdeaudhuij I, Van Holle V et al (2015) Reliability and validity of three questionnaires measuring context-specific sedentary behaviour and associated correlates in adolescents, adults and older adults. Int J Behav Nutr Phys Act 12:117. doi:10.1186/s12966-015-0277-2

Cawthon PM, Blackwell TL, Cauley J et al (2013) Objective assessment of activity, energy expenditure, and functional limitations in older men: the osteoporotic fractures in men study. J Gerontol A Biol Sci Med Sci 68:1518-1524. doi:10.1093/gerona/glt054 
Celis-Morales CA, Perez-Bravo F, Ibañez L et al (2012) Objective vs. self-reported physical activity and sedentary time: effects of measurement method on relationships with risk biomarkers. PLoS One 7:e36345. doi:10.1371/journal. pone. 0036345

Chase JM, Lockhart CK, Madden KM (2014) Accelerometerbased measures of sedentary behavior and cardio-metabolic risk in active older adults. Clin Investig Med 37:108-116

Chastin SFM, Granat MH (2010) Methods for objective measure, quantification and analysis of sedentary behaviour and inactivity. Gait Posture 31:82-86. doi:10.1016/j. gaitpost.2009.09.002

Chastin SFM, Ferriolli E, Stephens NA et al (2012) Relationship between sedentary behaviour, physical activity, muscle quality and body composition in healthy older adults. Age Ageing 41:111-114. doi:10.1093/ageing/afr075

Chastin SFM, Culhane B, Dall PM (2014a) Comparison of selfreported measure of sitting time (IPAQ) with objective measurement (activPAL). Physiol Meas 35:2319-2328. doi:10.1088/0967-3334/35/11/2319

Chastin SFM, Fitzpatrick N, Andrews M, DiCroce N (2014b) Determinants of sedentary behavior, motivation, barriers and strategies to reduce sitting time in older women: a qualitative investigation. Int J Environ Res Public Health 11:773-791. doi:10.3390/ijerph110100773

Chastin SFM, Mandrichenko O, Helbostadt JL, Skelton DA (2014c) Associations between objectively-measured sedentary behaviour and physical activity with bone mineral density in adults and older adults, the NHANES study. Bone 64:254-262. doi:10.1016/j.bone.2014.04.009

Clark BK, Winkler E, Healy GN et al (2013) Adults' past-day recall of sedentary time: reliability, validity, and responsiveness. Med Sci Sports Exerc 45:1198-1207. doi:10. 1249/MSS.0b013e3182837f57

Davis MG, Fox KR, Hillsdon M et al (2011) Objectively measured physical activity in a diverse sample of older urban UK adults. Med Sci Sports Exerc 43:647-654. doi:10. 1249/MSS.0b013e3181f36196

Davis MG, Fox KR, Stathi A et al (2014) Objectively measured sedentary time and its association with physical function in older adults. J Aging Phys Act 22:474-481. doi:10.1123/ japa.2013-0042

de Rezende LFM, Rey-López JP, Matsudo VKR, do Carmo Luiz O (2014a) Sedentary behavior and health outcomes among older adults: a systematic review. BMC Public Health 14:333. doi:10.1186/1471-2458-14-333

de Rezende LFM, Rodrigues Lopes M, Rey-López JP et al (2014b) Sedentary behavior and health outcomes: an overview of systematic reviews. PLoS One 9:e105620. doi:10.1371/journal.pone.0105620

Demiot C, Dignat-George F, Fortrat J-O et al (2007) WISE 2005: chronic bed rest impairs microcirculatory endothelium in women. Am J Physiol Heart Circ Physiol 293:H3159-H3164. doi:10.1152/ajpheart.00591.2007

Dogra S, Stathokostas L (2012) Sedentary behavior and physical activity are independent predictors of successful aging in middle-aged and older adults. J Aging Res 2012:190654. doi:10.1155/2012/190654

Dogra S, Stathokostas L (2014) Correlates of extended sitting time in older adults: an exploratory cross-sectional analysis of the
Canadian Community Health Survey Healthy Aging Cycle. Int J Public Health 59:983-991. doi:10.1007/s00038014-0540-3

Dunlop DD, Song J, Arnston EK et al (2015) Sedentary time in US older adults associated with disability in activities of daily living independent of physical activity. J Phys Act Health 12:93-101. doi:10.1123/jpah.2013-0311

Dunstan DW, Howard B, Healy GN, Owen N (2012a) Too much sitting - a health hazard. Diabetes Res Clin Pract 97:368376. doi:10.1016/j.diabres.2012.05.020

Dunstan DW, Kingwell BA, Larsen R et al (2012b) Breaking up prolonged sitting reduces postprandial glucose and insulin responses. Diabetes Care 35:976-983. doi:10.2337/dc111931

Ensrud KE, Blackwell TL, Cauley JA et al (2014) Objective measures of activity level and mortality in older men. J Am Geriatr Soc 62:2079-2087. doi:10.1111/jgs.13101

Evenson KR, Buchner DM, Morland KB (2012) Objective measurement of physical activity and sedentary behavior among US adults aged 60 Years or older. Prev Chronic Dis 9:2-11

Evenson KR, Morland KB, Wen F, Scanlin K (2014) Physical activity and sedentary behavior among adults 60 years and older: New York City residents compared with a national sample. J Aging Phys Act 22:499-507. doi:10.1123/japa. 2012-0345

Fitzsimons CF, Kirk A, Baker G et al (2013) Using an individualised consultation and activPAL ${ }^{\mathrm{TM}}$ feedback to reduce sedentary time in older Scottish adults: results of a feasibility and pilot study. Prev Med (Baltim) 57:718-720. doi:10.1016/j.ypmed.2013.07.017

Gao X, Nelson ME, Tucker KL (2007) Television viewing is associated with prevalence of metabolic syndrome in Hispanic elders. Diabetes Care 30:694-700. doi:10.2337/ dc06-1835

Gardiner PA, Clark BK, Healy GN et al (2011a) Measuring older adults' sedentary time: reliability, validity, and responsiveness. Med Sci Sports Exerc 43:2127-2133. doi:10.1249/MSS.0b013e31821b94f7

Gardiner PA, Eakin EG, Healy GN, Owen N (2011b) Feasibility of reducing older adults' sedentary time. Am J Prev Med 41:174-177. doi:10.1016/j.amepre.2011.03.020

Gardiner PA, Healy GN, Eakin EG et al (2011c) Associations between television viewing time and overall sitting time with the metabolic syndrome in older men and women: the Australian diabetes, obesity and lifestyle study. J Am Geriatr Soc 59:788-796. doi:10.1111/j.1532-5415.2011. 03390.x

Gardner B, Thuné-Boyle I, Iliffe S et al (2014) “On Your Feet to Earn Your Seat", a habit-based intervention to reduce sedentary behaviour in older adults: study protocol for a randomized controlled trial. Trials 15:368. doi:10.1186/ 1745-6215-15-368

Gennuso KP, Gangnon RE, Matthews CE et al (2013) Sedentary behavior, physical activity, and markers of health in older adults. Med Sci Sports Exerc 45:1493-1500. doi:10.1249/ MSS.0b013e318288a1e5

Gennuso KP, Matthews CE, Colbert LH (2015) Reliability and validity of 2 self-report measures to assess sedentary behavior in older adults. J Phys Act Health 12:727-732. doi:10.1123/jpah.2013-0546 
Gianoudis J, Bailey CA, Daly RM (2015) Associations between sedentary behaviour and body composition, muscle function and sarcopenia in community-dwelling older adults. Osteoporos Int 26:571-579. doi:10.1007/s00198-014-2895-y

Godfrey A, Lord S, Galna B et al (2014) The association between retirement and age on physical activity in older adults. Age Ageing 43:386-393. doi:10.1093/ageing/aft168

Gómez-Cabello A, Pedrero-Chamizo R, Olivares PR et al (2012) Sitting time increases the overweight and obesity risk independently of walking time in elderly people from Spain. Maturitas 73:337-343. doi:10.1016/j.maturitas. 2012.09.001

Gorman E, Hanson HM, Yang PH et al (2014) Accelerometry analysis of physical activity and sedentary behavior in older adults: a systematic review and data analysis. Eur Rev Aging Phys Act 11:35-49. doi:10.1007/s11556-0130132-x

Hamburg NM, McMackin CJ, Huang AL et al (2007) Physical inactivity rapidly induces insulin resistance and microvascular dysfunction in healthy volunteers. Arterioscler Thromb Vasc Biol 27:2650-2656. doi:10.1161/ATVBAHA.107.153288

Hamer M, Stamatakis E (2013) Screen-based sedentary behavior, physical activity, and muscle strength in the English longitudinal study of ageing. PLoS One 8:e66222. doi:10. 1371/journal.pone.0066222

Hamilton MT, Healy GN, Dunstan DW et al (2008) Too little exercise and too much sitting: inactivity physiology and the need for new recommendations on sedentary behavior. Curr Cardiovasc Risk Rep 2:292-298. doi:10.1007/ s12170-008-0054-8

Hart TL, Swartz AM, Cashin SE, Strath SJ (2011) How many days of monitoring predict physical activity and sedentary behaviour in older adults? Int J Behav Nutr Phys Act 8:62. doi:10.1186/1479-5868-8-62

Harvey JA, Chastin SFM, Skelton DA (2013) Prevalence of sedentary behavior in older adults: a systematic review. Int J Environ Res Public Health 10:6645-6661. doi:10.3390/ ijerph10126645

Harvey JA, Chastin SFM, Skelton DA (2015) How sedentary are older people? A systematic review of the amount of sedentary behavior. J Aging Phys Act 23:471-487. doi:10. 1123/japa.2014-0164

Healy GN, Dunstan DW, Salmon J et al (2008) Breaks in sedentary time: beneficial associations with metabolic risk. Diabetes Care 31:661-666. doi:10.2337/dc07-2046

Healy GN, Matthews CE, Dunstan DW et al (2011) Sedentary time and cardio-metabolic biomarkers in US adults: NHANES 2003-06. Eur Heart J 32:590-597. doi:10.1093/ eurheartj/ehq451

Hekler EB, Buman MP, Haskell WL et al (2012) Reliability and validity of CHAMPS self-reported sedentary- to-vigorous intensity physical activity in older adults. J Phys Act Health 9:225-236

Inoue S, Sugiyama T, Takamiya T et al (2012) Television viewing time is associated with overweight/obesity among older adults, independent of meeting physical activity and health guidelines. J Epidemiol 22:50-56. doi:10.2188/jea. JE20110054

Jefferis BJ, Sartini C, Ash S et al (2015a) Trajectories of objectively measured physical activity in free-living older men. Med Sci Sports Exerc 47:343
Jefferis BJ, Sartini C, Shiroma E et al (2015b) Duration and breaks in sedentary behaviour: accelerometer data from 1566 community-dwelling older men (British Regional Heart Study). Br J Sports Med 49:1591-1594. doi:10.1136/ bjsports-2014-093514

Kesse-Guyot E, Charreire H, Andreeva VA et al (2012) Crosssectional and longitudinal associations of different sedentary behaviors with cognitive performance in older adults. PLoS One 7:e47831. doi:10.1371/journal.pone.0047831

Kikuchi H, Inoue S, Sugiyama T et al (2013) Correlates of prolonged television viewing time in older Japanese men and women. BMC Public Health 13:213. doi:10.1186/1471-2458-13-213

Kikuchi H, Inoue S, Sugiyama T et al (2014) Distinct associations of different sedentary behaviors with health-related attributes among older adults. Prev Med (Baltim) 67:335339. doi:10.1016/j.ypmed.2014.08.011

Kim H, Iwasaki K, Miyake T et al (2003) Changes in bone turnover markers during 14-day 6 degrees head-down bed rest. J Bone Miner Metab 21:311-315. doi:10.1007/ s00774-003-0426-6

Kowalski K, Rhodes R, Naylor P-J et al (2012) Direct and indirect measurement of physical activity in older adults: a systematic review of the literature. Int J Behav Nutr Phys Act 9:148. doi:10.1186/1479-5868-9-148

Kozey Keadle S, Lyden K, Hickey A et al (2014) Validation of a previous day recall for measuring the location and purpose of active and sedentary behaviors compared to direct observation. Int J Behav Nutr Phys Act 11:12. doi:10.1186/ 1479-5868-11-12

Kozey-Keadle S, Libertine A, Lyden K et al (2011) Validation of wearable monitors for assessing sedentary behavior. Med Sci Sports Exerc 43:1561-1567. doi:10.1249/MSS. 0b013e31820ce174

Latouche C, Jowett JBM, Carey AL et al (2013) Effects of breaking up prolonged sitting on skeletal muscle gene expression. J Appl Physiol 114:453-460. doi:10.1152/ japplphysiol.00978.2012

Lenz EK (2014) Do sedentary behaviors modify the health status of older adults? Int J Kinesiol Sport Sci J Kinesiol Sport Sci J Kinesiol Sport Sci 2:13-22. doi:10.7575/aiac. ijkss.v.2n.1p.13

León-Muñoz LM, Martínez-Gómez D, Balboa-Castillo T et al (2013) Continued sedentariness, change in sitting time, and mortality in older adults. Med Sci Sports Exerc 45:15011507. doi:10.1249/MSS.0b013e3182897e 87

Letourneau K, Goodman JH (2014) A patient-centered approach to addressing physical activity in older adults: motivational interviewing. J Gerontol Nurs 40:26-33. doi:10.3928/ 00989134-20140819-01

Lohne-Seiler H, Hansen BH, Kolle E, Anderssen SA (2014) Accelerometer-determined physical activity and self-reported health in a population of older adults (65-85 years): a cross-sectional study. BMC Public Health 14:284. doi:10. 1186/1471-2458-14-284

Lord S, Chastin SFM, McInnes L et al (2011) Exploring patterns of daily physical and sedentary behaviour in communitydwelling older adults. Age Ageing 40:205-210. doi:10. 1093/ageing/afq166

Maeo S, Yamamoto M, Kanehisa H (2015) Muscular adaptations to short-term low-frequency downhill walking training. Int J Sports Med 36:150-156 
Marques EA, Baptista F, Santos DA et al (2014) Risk for losing physical independence in older adults: the role of sedentary time, light, and moderate to vigorous physical activity. Maturitas 79:91-95. doi:10.1016/j.maturitas.2014.06.012

Martin KR, Koster A, Murphy RA et al (2014) Changes in daily activity patterns with age in U.S. men and women: National Health and Nutrition Examination Survey 2003-04 and 2005-06. J Am Geriatr Soc 62:1263-1271. doi:10.1111/jgs. 12893

Martínez-Gómez D, Guallar-Castillón P, León-Muñoz LM et al (2013) Combined impact of traditional and non-traditional health behaviors on mortality: a national prospective cohort study in Spanish older adults. BMC Med 11:47. doi:10.1186/1741-7015-11-47

Matthews CE, Chen KY, Freedson PS et al (2008) Amount of time spent in sedentary behaviors in the United States, 2003-2004. Am J Epidemiol 167:875-881. doi:10.1093/ aje/kwm390

Matthews CE, Keadle SK, Sampson J et al (2013) Validation of a previous-day recall measure of active and sedentary behaviors. Med Sci Sports Exerc 45:1629-1638. doi:10. 1249/MSS.0b013e3182897690

Meneguci J, Sasaki JE, da Silva Santos Á et al (2015) Sociodemographic, clinical and health behavior correlates of sitting time in older adults. BMC Public Health 15:65. doi:10.1186/s12889-015-1426-x

Mitchell RJ, Lord SR, Harvey LA, Close JCT (2015) Obesity and falls in older people: mediating effects of disease, sedentary behavior, mood, pain and medication use. Arch Gerontol Geriatr 60:52-58. doi:10.1016/j.archger.2014.09.006

Nicklas BJ, Gaukstern JE, Beavers KM et al (2014) Self-monitoring of spontaneous physical activity and sedentary behavior to prevent weight regain in older adults. Obesity (Silver Spring) 22:1406-1412. doi:10.1002/oby.20732

Owen N, Sugiyama T, Eakin EE et al (2011) Adults' sedentary behavior determinants and interventions. Am J Prev Med 41:189-196. doi:10.1016/j.amepre.2011.05.013

Pate RR, Neill JRO, Lobelo F (2008) The evolving definition of "'Sedentary.", 29208:173-178

Patel AV, Bernstein L, Deka A et al (2010) Leisure time spent sitting in relation to total mortality in a prospective cohort of US adults. Am J Epidemiol 172:419-429. doi:10.1093/ aje/kwq155

Pavey TG, Peeters GG, Brown WJ (2015) Sitting-time and 9 -year all-cause mortality in older women. Br J Sports Med 49:95-99. doi:10.1136/bjsports-2012-091676

Peddie MC, Bone JL, Rehrer NJ et al (2013) Breaking prolonged sitting reduces postprandial glycemia in healthy, normalweight adults: a randomized crossover trial. Am J Clin Nutr 98:358-366. doi:10.3945/ajcn.112.051763

Pedišić Ž, Bauman A (2015) Accelerometer-based measures in physical activity surveillance: current practices and issues. $\mathrm{Br}$ J Sports Med 49:219-223. doi:10.1136/bjsports-2013-093407

Pronk NP, Katz AS, Lowry M, Payfer JR (2012) Reducing occupational sitting time and improving worker health : the take-a-stand project, 2011. Prev Chronic Dis 9:1-9

Rhodes RE, Mark RS, Temmel CP (2012) Adult sedentary behavior: a systematic review. Am J Prev Med 42:e3-e28. doi:10.1016/j.amepre.2011.10.020

Santos DA, Silva AM, Baptista F et al (2012) Sedentary behavior and physical activity are independently related to functional fitness in older adults. Exp Gerontol 47:908912. doi:10.1016/j.exger.2012.07.011

Sardinha LB, Santos DA, Silva AM et al (2015) Breaking-up sedentary time is associated with physical function in older adults. J Gerontol A Biol Sci Med Sci 70:119-124. doi:10. 1093/gerona/glu193

Sedentary Behaviour Research Network (2012) Letter to the editor: standardized use of the terms "sedentary" and "sedentary behaviours". Appl Physiol Nutr Metab 37:540-542. doi:10.1139/h2012-024

Shiroma EJ, Freedson PS, Trost SG, Lee I-M (2013) Patterns of accelerometer-assessed sedentary behavior in older women. JAMA 310:2562-2563. doi:10.1001/jama.2013.278896

Stamatakis E, Davis M, Stathi A, Hamer M (2012) Associations between multiple indicators of objectively-measured and self-reported sedentary behaviour and cardiometabolic risk in older adults. Prev Med (Baltim) 54:82-87. doi:10.1016/ j.ypmed.2011.10.009

Steinberg SI, Sammel MD, Harel BT et al (2015) Exercise, sedentary pastimes, and cognitive performance in healthy older adults. Am J Alzheimers Dis Other Demen 30:290-298. doi:10.1177/1533317514545615

Thosar SS, Bielko SL, Mather KJ et al (2015) Effect of prolonged sitting and breaks in sitting time on endothelial function. Med Sci Sports Exerc 47:843-849. doi:10.1249/ MSS.0000000000000479

Tomlinson DJ, Erskine RM, Morse CI et al (2014) Combined effects of body composition and ageing on joint torque, muscle activation and co-contraction in sedentary women. Age (Dordr) 36:9652. doi:10.1007/s11357-014-9652-1

Tremblay MS, Colley RC, Saunders TJ et al (2010) Physiological and health implications of a sedentary lifestyle. Appl Physiol Nutr Metab 35:725-740. doi:10.1139/H10-079

Uffelen V, Jannique GZ, Gellecum V, Yolanda R (2012) Which older women could benefit from interventions to decrease sitting time and increase physical activity? Jannique GZ van Uffelen, $\mathrm{PhD} * \dagger$ Kristiann $\mathrm{C}$ Heesch, $\mathrm{PhD} \S$ Yolanda $\mathrm{R}$ van Gellecum * Nicola W Burton, PhD * Wendy J Brown, $\mathrm{PhD} * *$ The Universit

Van Cauwenberg J, De Donder L, Clarys P et al (2014a) Relationships of individual, social, and physical environmental factors with older adults' television viewing time. J Aging Phys Act 22:508-517. doi:10.1123/japa.2013-0015

Van Cauwenberg J, Van Holle V, De Bourdeaudhuij I et al (2014b) Older adults' reporting of specific sedentary behaviors: validity and reliability. BMC Public Health 14:734. doi:10.1186/1471-2458-14-734

van der Berg JD, Bosma H, Caserotti P et al (2014) Midlife determinants associated with sedentary behavior in old age. Med Sci Sports Exerc 46:1359-1365. doi:10.1249/MSS. 0000000000000246

van Uffelen JGZ, Heesch KC, Hill RL, Brown WJ (2011) A qualitative study of older adults' responses to sitting-time questions: do we get the information we want? BMC Public Health 11:458. doi:10.1186/1471-2458-11-458

Vance DE, Webb NM, Marceaux JC et al (2008) Mental Stimulation, Neural Plasticity, and Aging. J Neurosci Nurs 40:241-249. doi:10.1097/01376517-200808000-00008

Verghese J, Lipton RB, Katz MJ et al (2003) Leisure activities and the risk of dementia in the elderly. N Engl J Med 348:2508-2516. doi:10.1056/NEJMoa022252 
Visser M, Koster A (2013) Development of a questionnaire to assess sedentary time in older persons-a comparative study using accelerometry. BMC Geriatr 13:80. doi:10. 1186/1471-2318-13-80

Withall J, Stathi A, Davis M et al (2014) Objective indicators of physical activity and sedentary time and associations with subjective well-being in adults aged 70 and over. Int J
Environ Res Public Health 11:643-656. doi:10.3390/ ijerph110100643

Yates T, Khunti K, Wilmot EG et al (2012) Self-reported sitting time and markers of inflammation, insulin resistance, and adiposity. Am J Prev Med 42:1-7. doi:10.1016/j.amepre. 2011.09.022 